Gut, 1986, 27, 1357-1361

\title{
Postnatal development of disaccharidase activities in jejunal fluid of preterm neonates
}

\author{
ANDREA J MAYNE, G A BROWN, DIANA SULE, AND A S MCNEISH \\ From the University of Birmingham, Institute of Child Health, Edgbaston, Birmingham
}

SUMmARY Because human fetuses of 26-30 weeks gestation are known to have low levels of intestinal mucosal lactase activity, it has been assumed that live born preterm neonates of comparable gestational age are also lactase deficient. We have previously shown that disaccharidase activities in jejunal fluid in infants are highly significantly correlated with enzyme activities in the adjacent mucosa. We have now measured disaccharidase activities crosssectionally and longitudinally in the jejunal fluid of a group of very preterm neonates of 26-29 weeks gestation who were fed with pasteurised human milk. Lactase activity was within the normal range for older infants and children within the first week of life. Sucrase: lactase ratios fell significantly in the second and third weeks of life, strongly suggesting a further increase in lactase activity. This increase was independent of postconceptional age. Preterm neonates are not as lactase deficient as previously believed, and this has implications in the search for optimal feeding regimes.

The increasing survival of extremely preterm neonates is posing new problems, and in particular the need to define satisfactory feeding regimes. Current knowledge ${ }^{1}$ suggests that these infants are deficient in intestinal lactase and this has led to recommendations that the carbohydrate in the diet of these infants should not be lactose. ${ }^{2}$

The evidence for lactase deficiency is based on studies of fetuses and non-viable neonates. Dahlqvist and Lindberg ${ }^{3}$ showed that lactase activity in fetuses of 23 weeks gestation was only $10 \%$ of adult levels. Auricchio et $a l^{4}$ found low lactase levels in non-viable infants of 8 months gestation. Antonowicz and Lebenthal ${ }^{5}$ demonstrated that lactase levels in non-viable fetuses of 26-34 weeks gestation were $30 \%$ of the levels in full term infants.

There are obvious pitfalls in attempting to impose fetal data on living neonates and the above results certainly conflict with the clinical observation that small, preterm infants frequently tolerate human milk (which contains approximately $7 \mathrm{~g} / \mathrm{dl}$ lactose) without showing clinical signs of lactose intolerance. ${ }^{6}$ To resolve this conflict a technique is needed that will allow levels of these disaccharidases to be measured in living neonates.

Address for correspondence: Dr A J Mayne, Institute of Child Health, Francis Road, Edgbaston, Birmingham, B16 8ET.

Received for publication 14 February, 1986
We have previously shown in older infants and children that disaccharidase levels in jejunal fluid are significantly correlated $(\mathrm{p}<0.001)$ with enzyme activities in the adjacent mucosa ${ }^{7}$ and, in a preliminary communication, that the technique can be applied in the newborn. ${ }^{8}$ This paper describes for the first time, cross sectional and longitudinal studies of disaccharidase activities in jejunal fluid of preterm viable neonates to try to determine the patterns of postnatal development of these enzymes.

\section{Methods}

PATIENTS

Infants

All infants studied were inpatients in the Neonatal Unit of Birmingham Maternity Hospital. Birth weight was recorded, and gestational age was estimated from maternal 'dates' confirmed by ultrasound examination and Dubowitz scoring. ${ }^{9}$ Eight preterm, appropriate for gestational age infants were studied on 17 occasions in the first three weeks of life. All were enterally fed with pasteurised expressed breast milk. The gestational ages ranged from 26-29 weeks (mean 28 weeks) and the birth weights were $880-1420 \mathrm{~g}$ (mean $1143 \mathrm{~g}$ ). The postnatal changes in disaccharidase activities were followed in five of these infants who were studied on two to three occasions (mean 2.6) with an average of 
six days (range three to eight days) between investigations. Informed consent was obtained from the parents of each baby, and the project was approved by the local Ethical Committee.

\section{JEJUNAL INTUBATION}

All infants were fed by nasogastric tubes which were changed regularly as part of routine nursing care. At these times, and approximately 10 minutes before a regular feed, a FG04 (Vygon) nasojejunal tube was passed into the upper small intestine, without recourse to radiology, by a previously described technique. ${ }^{10}$ After a sample of jejunal fluid was obtained, the tube was withdrawn to the stomach and used thereafter as a conventional feeding tube.

\section{ASSAY OF DISACCHARIDASE ACTIVITIES IN}

\section{JEJUNAL FLUID}

All specimens were stored at $-20^{\circ} \mathrm{C}$ until analysed. Maltase, sucrase, and lactase activities were measured using the micromethod of Peters et al. ${ }^{11}$ Jejunal fluid was diluted 10 -fold for sucrase and lactase and 40 -fold for maltase estimations. One hundred microlitres of the diluted fluid were assayed in duplicate with analytical control fluid specimens included in each batch. Enzyme activities were expressed in units/l fluid ( 1 unit $=1 \mu$ mol substrate hydrolysed/minute at $\mathrm{pH} 6.0$ and $37^{\circ} \mathrm{C}$.) The nonparametric Mann-Whitney U-test was used for statistical analysis of the results.

\section{Results}

Figure 1 shows the disaccharidase levels measured in the jejunal fluid during the first week of life, and the second and third weeks of life. The mean values of maltase, sucrase, and lactase activities in the first week of life all fell within the normal range for a group of older children 10 months to 14 years (mean 5.9 years) studied in our laboratory by Aramayo. ${ }^{7}$ Of particular note was the mean value for lactase which was $14 \cdot 1 \pm 5.8 \mathrm{U} / \mathrm{l}(\mathrm{x} \pm \mathrm{SEM})$ with all the values falling within the normal reference range. There was no significant difference between the absolute values of enzymes from the first and the second plus third weeks of life.

The large scatter of results and high standard errors may be contributed to by dilutional factors. The infants were not fasted and variable quantities of intestinal secretion may have led to varying dilution of the jejunal fluids. To overcome this problem the relative proportions of the disacchar-
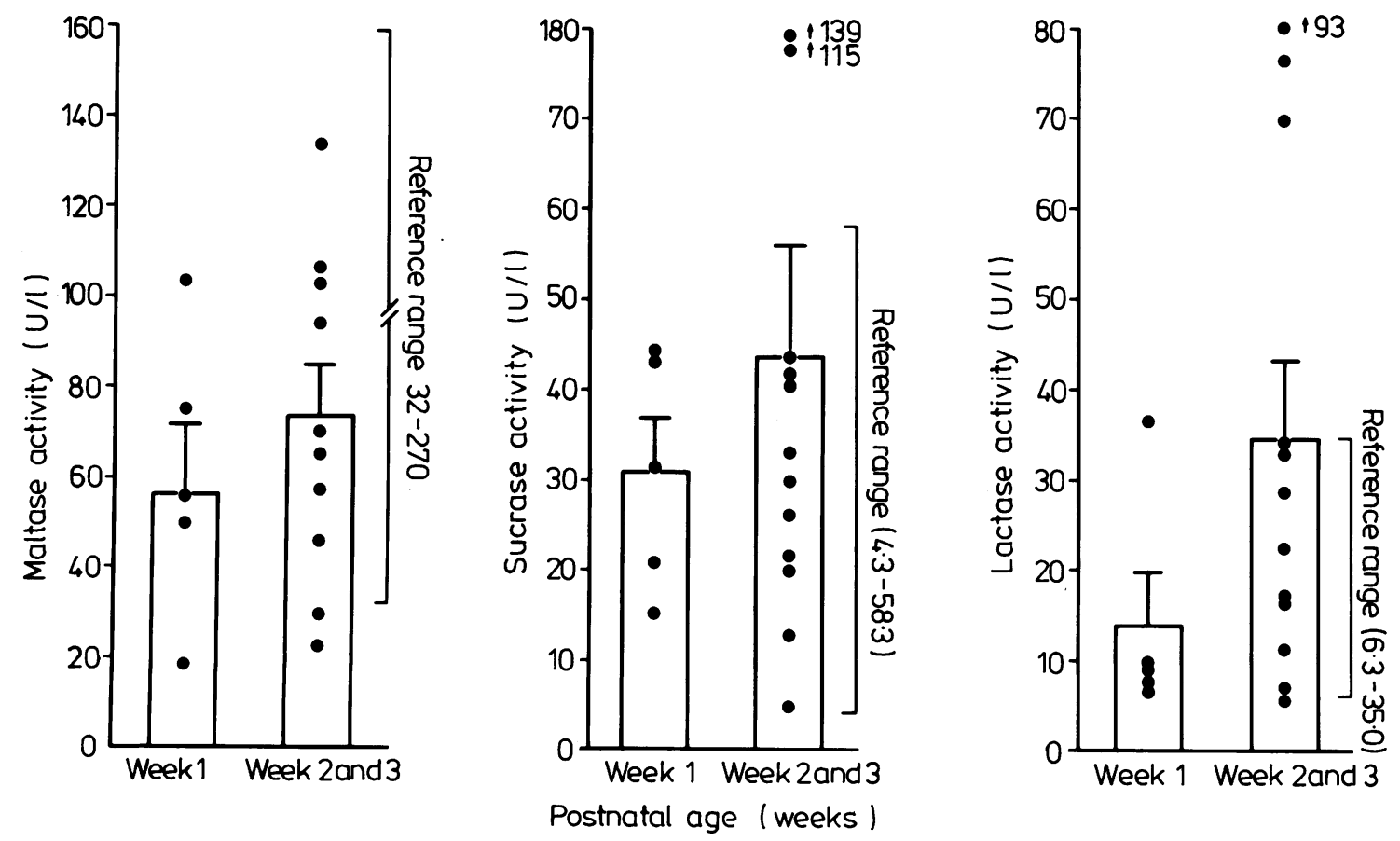

Fig. 1. Individual disaccharidase activities in jejunal fluid during the first, and second and third (combined) weeks of life. The reference ranges, in this and subsequent figures, are from Aramayo et al. ${ }^{7}$ 


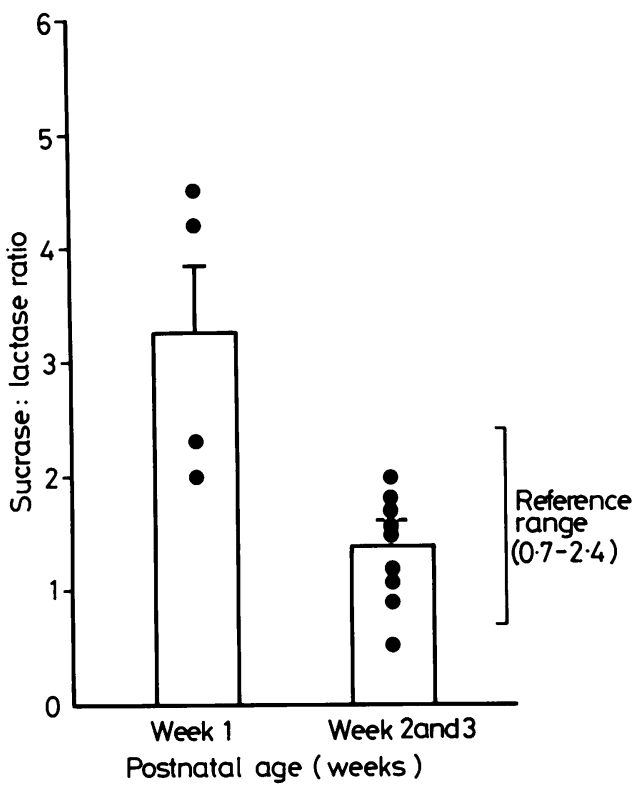

Fig. 2. Ratios of sucrase: lactase activities in jejunal fluid showing a significant fall $(p<0 \cdot 001)$ from 1 week to week 2 and 3 . idases were examined. We have made the assumption that sucrase activity is similar in late gestation and the early postnatal period. All the available data $^{125}$ support this concept. The sucrase:lactase ratio was calculated in the five infants studied longitudinally. The results are shown in Figure 2 . The mean sucrase:lactase ratio in the first week of life was $3.3 \pm 0.6$ (range 2.0 to 4.5 ) and fell significantly $(\mathrm{p}<0.001)$ to $1.4 \pm 0.2$ (range 0.5 to 1.99 ) in the second and third weeks of life. Figure 3 shows the individual longitudinal data from these five infants. The fall in sucrase:lactase ratio by weeks two and three was consistently demonstrated.

\section{Discussion}

It is widely recognised and agreed that intestinal sucrase activity appears early in human fetal development and that activity approaching adult values can be found before the end of the second trimester. $^{3-5}$ In contrast the pattern of lactase development is less clear.

Superficial analysis of the available data ${ }^{3-5}$ justifies the conventional view that 'lactase activity is very low and remains so until 32 weeks when it rapidly increases to reach a maximum just before

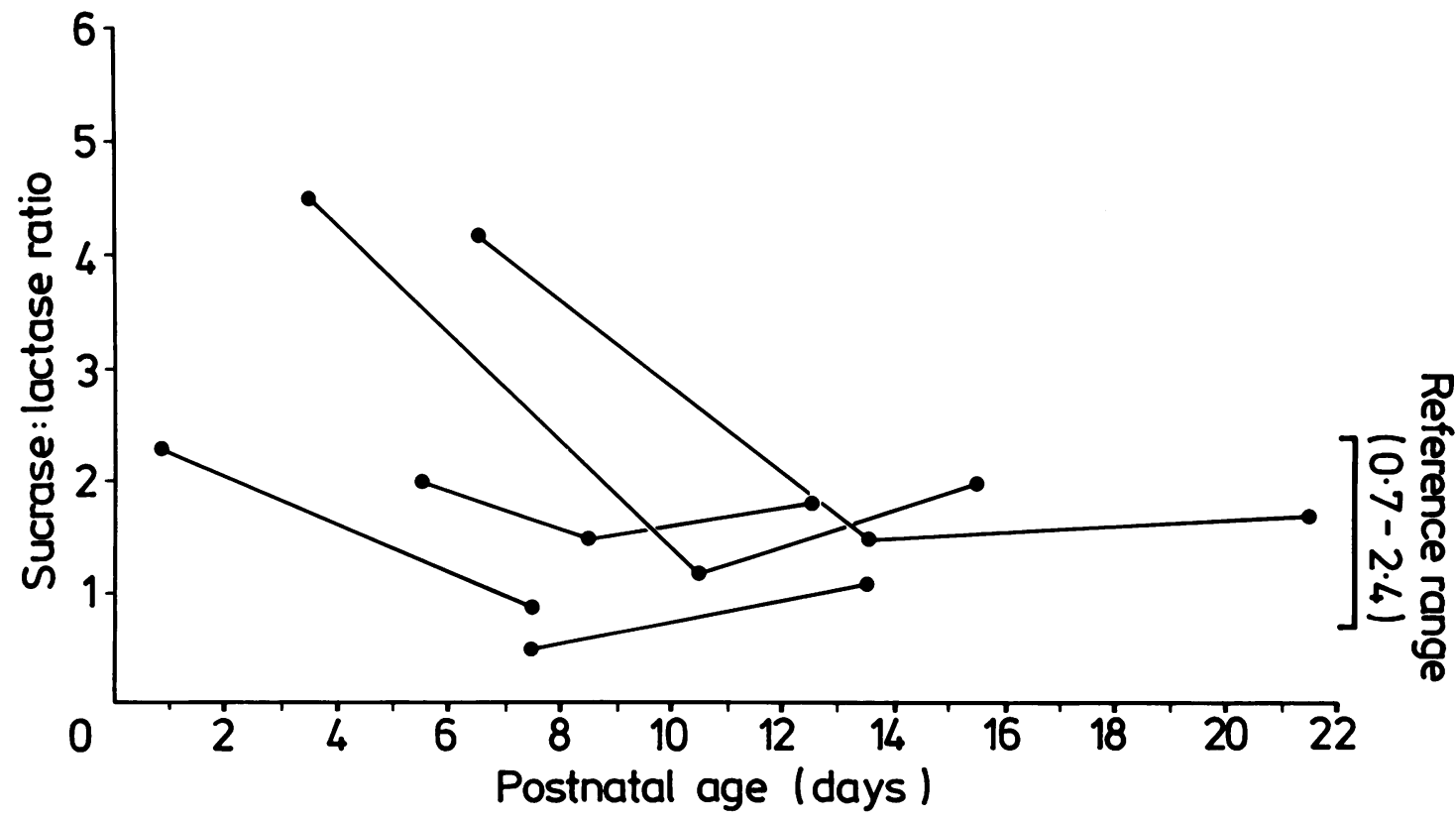

Fig. 3. Serial measurements of sucrase: lactase ratios in jejunal fluid of 5 infants studies 2 to 3 times in the first three weeks of life. 
birth'. ${ }^{12}$ Until the present time, these fetal data have been assumed to reflect the enzyme activities that occur in preterm infants. There have been no direct observations on viable living neonates although a small number of live born infants who died shortly after birth have been studied.

Auricchio $\mathrm{et} \mathrm{al}^{4}$ studied three preterm infants of 7 to 8 months gestation who survived more than one day and who had been fed. Lactase activity in those infants was $50 \%$ higher than in three still births of the same gestational age. Eggermont ${ }^{13}$ reported that a 29 weeks preterm infant of $1220 \mathrm{~g}$, surviving $38 \mathrm{~h}$, had lactase levels within the normal adult range. It is not stated whether or not the infant was fed during life. Antonowicz et al $^{14}$ showed in a single preterm infant of 28 weeks, who survived 10 days, that lactase activity was twice the mean value for infants of 2 to 11 months.

Although the authors of these papers do not discuss the significance of the findings in these nonviable cases, it seems reasonable to assume that they illustrate the same trend or process that has been shown in the present study.

The technique described in the present paper has allowed for the first time an estimate of intestinal disaccharidase activity in living neonates. The mean lactase activity of $14 \cdot 1 \pm 5 \cdot 8 \mathrm{U} / 1$ in the first week of life is itself within normal limits for older infants, ${ }^{7}$ but only half the mean value in the second and third weeks $(34 \cdot 8 \pm 8.4 \mathrm{U} / \mathrm{l})$. The highly significant fall $(p<0.001)$ in the sucrase:lactase ratio between the first and subsequent weeks suggests strongly a true increase in lactase activity over this period and the pattern was consistent in each infant studied.

The gestational age range of 26 to 29 weeks did not affect the timing of the fall of the sucrase:lactase ratio, suggesting that the rise in lactase activity is independent of postconceptional age but could be triggered by birth and/or feeding. Ethical constraints made more accurate timing of the rise in lactase activity impossible as jejunal intubation was only carried out when nasogastric tubes were routinely changed. All our infants in the study were fed enterally with pasteurised, expressed breast milk from the first day of life as part of the normal routine of the neonatal unit. It is therefore difficult to speculate whether the birth process itself or feeding influences the rise in lactase activity.

It was possible, however, to study one infant of 28 weeks gestation weighing $880 \mathrm{~g}$ who did not tolerate enteral feeding and who was parenterally fed for the first three weeks of life, enteral feeding then being gradually reintroduced. This child was studied on four occasions on days seven, 24,36 , and 42 of life. The sucrase:lactase ratio was $2.9,1 \cdot 5,0 \cdot 8$, and 1.7 respectively. The maximum rise in lactase activity (lowest sucrase:lactase ratio) occurred at the beginning of the sixth week of life. This delay in the rise in lactase activity, compared with our study group could support the hypothesis that feeding has an influence on lactase activity that is superimposed on the underlying developmental clock but many more data are needed to support such speculation.

The suggestion from the present study that very preterm infants can have lactase activities comparable with older infants does not mean that preterms have the same capacity to hydrolyse lactose as full term infants, for at least three reasons. First we have assessed enzyme activity in the proximal small intestine only and this may not correlate accurately with the 'functional capacity' of the intestine for substrate. ${ }^{2}{ }^{15}$ Second, Grand et al ${ }^{1}$ superimposed the data from several studies on the ontogeny of lactase and concluded that lactase levels at term are two to four times the values found in normal infants of 2-11 months of age. Third, the tolerance of preterm neonates to dietary lactose may be attributable in part to colonic salvage. ${ }^{16}$

More studies are clearly needed of the relationship between birth, feeding, enzyme development and nutritional capacity of the intestine in preterm infants. In the meantime, we cannot agree with Lebenthal $e t a l^{2}$ who, extrapolating from fetal data, concluded that infants born during the eighth month of gestation can utilise (other sugars) reasonably well, but not lactose.'

We are grateful to Dr G M Durbin and nursing staff at the Neonatal Unit, Birmingham Maternity Hospital, for their interest, and for their permission to study infants in their care. This work was carried out during the tenure of a Sheldon Fellowship awarded to Dr Andrea J Mayne by the West Midlands Regional Health Authority.

\section{References}

1 Grand RJ, Watkins JB, Torti FT. Development of the human gastrointestinal tract: a review. Gastroenterology 1976; 70: 790-810.

2 Lebenthal E, Lee PC, Heitlinger LA. Impact of the development of the gastrointestinal tract on infant feeding. J Pediatr 1983; 102: 1-9.

3 Dahlqvist A, Lindberg T. Development of the intestinal disaccharidase and alkaline phosphatase activities in the human foetus. Clin Sci 1966; 30: 517-28.

4 Auricchio S, Rubino A, Murset G. Intestinal glycosidase activities in the human embryo, fetus and newborn. Pediatrics 1965; 35: 944-54.

5 Antonowicz I, Lebenthal E. Developmental pattern of small intestinal enterokinase and disaccharidase activities in the human fetus. Gastroenterology 1977; 72: 1299-303. 
6 Pearce JL, Buchanan LF. Breast milk and breast feeding in very low birthweight infants. Arch Dis Child 1979; 54: 897-9.

7 Aramayo LA, De Silva DGH, Hughes CA, Brown GA, McNeish AS. Disaccharidase activities in jejunal fluid. Arch Dis Childh 1983; 58: 686-91.

8 Mayne A, Hughes CA, Sule D, Brown GA, McNeish AS. Development of intestinal disaccharidases in preterm infants. Lancet 1983; ii: 622-3.

9 Dubowitz L, Dubowitz V. The neurological assessment of the preterm and fullterm newborn infant. Clinics in developmental medicine. No. 79. London: Heinemann, 1981.

10 Ducker DA, Hughes CA, Warren I, McNeish AS. Neonatal gut function, measured by the one hour blood $\mathrm{D}(+)$ xylose test: influence of gestational age and size. Gut 1980; 21: 133-6.

11 Peters TJ, Batt RM, Heath JR, Tilleray J. The micro- assay of intestinal disaccharidases. Biochem Med 1976; 15: $145-8$.

12 McCollum JPK, Milla PJ. Prenatal development of structure and function. In: JT Harries, ed. Essentials of paediatric gastroenterology London: Churchill Livingstone, 1977: 1-15.

13 Eggermont E. Enzymatic activities in meconium from human fetuses and newborns. Biol Neonate 1966; 10: 266-80.

14 Antonowicz I, Chang SK, Grand RJ. Development and distribution of lysosomal enzymes and disaccharidases in human fetal intestine. Gastroenterology 1974; 67: 51-8.

15 Hirata Y, Matsuo P, Kobubu H. Digestion and absorption of milk protein in infants' intestine. Kobe $J$ Med Sci 1965; 11: 103-9.

16 MacLean WC, Fink BB. Lactose malabsorption by preterm infants: Magnitude and clinical significance. $J$ Pediatr 1980; 97: 383-8. 